\title{
Impact of using 2D Animation As a Pedagogical Tool
}

M.H.M Wickramasinghe, Department of Software Engineering, University of Kelaniya, Kelaniya, Srilanka. Email-manuwickey889@gmail.com

M.M.T Wickramasinghe, Department of Management of Technology, University of Moratuwa,Moratuwa,Sri Lanka. Email-thrisara94@gmail.com

\begin{abstract}
21st-century knowledge economy driven modern curriculum needs students to perceive complex dimensions of knowledge to be intellectually competent [1]The authors have observed that animation is an excellent way of presenting academics in a less complicated form to students as the concepts can be presented lively and engaging students visually. It has been found out that the platform and the learning atmosphere impact on data mining [2] This study was conducted with the main objective to assess the impact of using 2D animation as an effective teaching tool and to evaluate the most effective learning atmosphere for undergraduate studies. The authors have incorporated a qualitative approach to systematically investigate in-depth the effective use of 2D animation as a teaching tool. The authors have selected 180 business management undergraduate students as the sample of this study. The sample was divided in to two groups where each group comprised of 90 students. One group of students were taught using the 2D animated videos using animated characters relevent to the course module and the other group of students were taught using only the presentation slides created throughMicrosoft power point using only text and images. Through thematic analysis and participant observations, it was found out that there is a direct effect of using animated characters as a teaching tool and it was found out that using 2D animations add more value to the role of a lecturer when delivering through online platforms. This study's findings contribute towards emphasising how effective and innovative teaching techniques can be developed using 2D animations in a classroom environment. Thereby, through positive enhancement of the next generation of leaders' knowledge and attitudes in our country will increase the human intelligence assets in the knowledge-driven economy.
\end{abstract}

Keywords:

2DAnimation, Pedological tool, Learning theory

Article Received: 18 October 2020, Revised: 3 November 2020, Accepted: 24 December 2020

\section{Introduction}

This is an era where technology has taken over every aspect of the lives of humankind. Highly dynamic changes in the technological environment have arisen the need to adopt for those changes to achieve success in a global platform. Researchers have observed the need to incorporate innovative teaching techniques to break monotonous nature and ensure the effective delivery of complex phenomena delivered fitting to the learning atmosphere.Traditionally, theories and concepts were mainly delivered through classroom environments [3]

However, COVID 19 pandemic situation aroused the need for innovatively using technology and adopting effective online teaching techniques. Analysing through the blooms taxonomy model of evaluating the effectiveness and quality of learning, researchers have observed the need to evaluate effective ways of using technology creatively in a way where the learner can remember, understand, analyse, and create knowledge through acquiring new knowledge to develop intellectual capabilities demanded for 21 'st century. The researchers have observed that $2 \mathrm{D}$ animation is a cost-effective technique that could be incorporated into online teaching. This systematic investigation is driven by the main research question of 'what is the impact of using 2D animation as a pedagogical tool in online teaching?'. The main research objectives of the study include,critical evaluation of the existing course materials, analysisof the most effective animated videos which could be incorporated to teach strategic management module, critical evaluation of the student enagement,active 
participation of the students, emotional expressions of the participants, and assessments in order to conduct a critical analysis of the impact of using 2D animation as a pedagogical tool.

\section{II.Research Methodology}

To achieve the above objectives, the authors have incorporated a qualitative approach and has used thematic analysis and participant observations as the main technique to analyse the gathered data. The study population includes undergraduate students in Sri Lanka. The target population includes undergraduate students at a leading businessmanagement university atSri Lanka. The study sample included180 students from second-year business managementundergraduate students, at the leading businessmanagement university atSri Lanka.The sample was divided in to two groups where each group comprised of 90 students. One group of students were taught using the 2D animated videos and the other group of students were taught using only the presentation slides created through
Microsoft power point using only texts and imagesAuthors have used purposive sampling method in order to select the study sample. Due to the prevailing situation of the country with limitations to conduct field visits, researchers have used online platforms to conduct interviews and to assess the effectiveness of using 2D animations in online lecture delivery. Researchers have mainly collected data through primary sources such as focus group interviews through zoom (online platform) with a selected sample of undergraduate students, participant observations zoom online platform with their camera on, structured and semi-structured telephone interviews with experts in the education field. Authors have gathered data through secondary sources such as case studies, educational videos created using 2D animations, books on learning theory and collaborative learning theory to systematically investigate the context.

\subsection{Descriptive Statistics of the Two Groups}

\section{Table 2.1 Descriptive statistics of attendance for all four days of lectures}

\section{Group A Group B}

Used 2D animated video as a pedagogical tool through Microsoft

$\mathrm{n}=90$

$\mathrm{n}=90$
Used only Power point presentation slides created

Power Point

\begin{tabular}{|c|c|c|}
\hline Value & Frequency & $\begin{array}{l}\text { Valid } \\
\text { Percent }\end{array}$ \\
\hline \multicolumn{3}{|c|}{ Attendance for all four days of lectures } \\
\hline \multicolumn{3}{|l|}{ Present only for one day } \\
\hline Present for two days & 5 & 5.6 \\
\hline Present for three days day & 10 & 11.1 \\
\hline Present all four days & 75 & 83.3 \\
\hline Total & 90 & 100.0 \\
\hline
\end{tabular}

\section{Source: Generated through SPSS software}

Refering to the table 2.1Descriptive statistics of attendance for all four days of lectures, the group of studentwho learnt using 2D animated videos demonstrated a positive results increasing the number of days they attended to the lectures,

\begin{tabular}{l|l|}
\hline 4 & 4.4 \\
\hline 8 & 8.9 \\
\hline 48 & 53.3 \\
\hline 30 & 33.3 \\
\hline 90 & 100.0 \\
\hline
\end{tabular}

whereas the other group of students who did not use 2D animated videos demonstrated the usual pattern of attendance to the lectures. $83 \%$ from the group of student wholearnt using 2D animated videos (group A), attended all four days of 
lectures, whereas the other group (group B) who was not exposed to 2D animation based learning was $33 \%$. There were also students from the group $\mathrm{B}$ who only attended one day of the lectures whereas, there weren't any students from group A who attended only one day as they were interested on the lectures and showed an enthusiasm to participate in the lectures. Authorsobserved that the participants who were exposed to 2D animation based learning was curious to know what kind of animation characters will be used for the coming lectures and it made them easier to gain an interest to learn through curiosity and enjoyment.

\section{Table 2.2 Descriptive statistics of engagement towards the lesson}

\section{Group A Group B}

Used 2D animated video as a pedagogical tool Used only Power point presentation slides created through Microsoft

$\mathrm{n}=90$

Power Point

$\mathrm{n}=90$

\begin{tabular}{|c|c|c|}
\hline Value & Frequency & $\begin{array}{l}\text { Valid } \\
\text { Percent }\end{array}$ \\
\hline
\end{tabular}

\begin{tabular}{l|l|l|}
\hline Positive & 69 & 76.7 \\
\hline Neutral & 21 & 23.3 \\
\hline Negative & - & - \\
\hline Total & 90 & 100.0 \\
\hline
\end{tabular}

\begin{tabular}{l|l|l}
\cline { 2 - 3 } Engagemen & 12 & 13.3 \\
\cline { 2 - 3 }$t \quad$ towards & 60 & 66.7 \\
\cline { 2 - 3 } the lesson & 18 & 20.0 \\
\cline { 2 - 3 } & 90 & 100.0 \\
\hline
\end{tabular}

Source: Generated through SPSS software

Refering to the table 2.2Descriptive statistics of engagement towards the lesson, the group of student who learnt using 2D animated videos demonstrated a positive results through asking constructive questions and critical evaluations regarding the concepts taught,whereas the other group of students who did not use 2D animated videos demonstrated the usual pattern of enagement towards the lesson. $77 \%$ from the group of student who learnt using 2D animated videos (group A), raised questions which were beneficial to the other learners as well. Majority of the students from group A conducted a critical debate on the taught concept, whereas the constructive questions raised by the other group (group B) who was not exposed to 2D animation based learning was only $13 \%$ and among those who raised questions were the students who usually engage with the lesson on the other lecture days as well. There were only $23 \%$ kept silent throughout the lecture from group A whereas, there were $60 \%$ from group B.There were 18 students from group B who left the lecture in between the session and did not joined back. From the group who were exposed to 2D animation based learning, there weren't any students who left the session in between. Aurthors observed that there were 10 students who had technical issues and they got disconnected due to poor signal and technical issues, however all of them somehow managed to solve the issues that they faced and rejoined the lecture taking not more than 10 minutes.

\section{Table 2.3 Descriptive statistics of emotions of the participants}

\section{Group A Group B}

Used 2D animated video as a pedagogical tool through Microsoft
Used only Power point presentation slides created 
$\mathrm{n}=90$

Power Point

$\mathrm{n}=90$

\begin{tabular}{lcl}
\hline Value & Frequency & $\begin{array}{l}\text { Valid } \\
\text { Percent }\end{array}$ \\
\hline Emotions of the participants & \\
\hline Happy & 74 & 82.2 \\
\hline Boredom & 16 & 17.8 \\
\hline Total & 90 & 100.0 \\
\hline
\end{tabular}

Source: Generated through SPSS software

Refering to the table 2.3Descriptive statistics of the emotions expressed by the participants, majority of the group of student who learnt using 2D animated videosexpressed happiness through their facial expressions. $82 \%$ from group A who was exposed to 2D animations based learning expressed pleasant gestures and facial moments such as relaxed lips, crows feet wrinkles when smiling, and nodding the head with relaxed facial muscles where as only $18 \%$ of the students expressed gestures which shows boredom such as yawing, dragging face and sleepy eyes. Whereas, the other group (group B) who was not exposed to 2D animations based learning showed the entire opposite results. The majority expressed gestures which shows boredom which came up to $77 \%$.Only $23 \%$ expressed happy emotions such as relaxed lips and nodding the head with relaxed facial muscles.

Table 2.4 Descriptive statistics of evaluation after lecture through MCQ and viva presentation assessment Group A Group B

Used $2 \mathrm{D}$ animated video as a pedagogical tool through Microsoft

$\mathrm{n}=90$

Used only Power point presentation slides created

$\mathrm{n}=90$

Value Frequency Valid Percent

Power Point

\section{Evaluation after lecture through MCQ and viva presentation assessment}

\begin{tabular}{l|l|l|l|c|}
\hline $30-50$ & 13 & 14.4 & 18 & 20.0 \\
\hline $51-69$ & 28 & 31.1 & 32 & 35.6 \\
\hline $70-79$ & 15 & 16.7 & 12 & 13.3 \\
\hline $80-100$ & 34 & 37.8 & 28 & 31.1 \\
\hline Total & 90 & 100.0 & 90 & 100.0 \\
\hline
\end{tabular}

\section{Source: Generated through SPSS software}

Refering to the table 2.4Descriptive statistics of theevalution taken after three weeks of the lectures through an MCQ assessment and viva presentation, majority of the group of student who learnt using 2D animated videos demonstrated a less percentage of lower grades than the group who was not exposed to any 2D animation based learning. Researchers found interesting findings through the final evalution assessment. Eventhough, both the groups demonstratescloser percentages for the higher grades, through the focus group interviews and participant 
observations researchers found out that the group who was exposed to $2 \mathrm{D}$ animation were able to engage in other extra curricular activities as they had time to manage both the studies and other extra curricular activities. The group who were not exposed to 2D animation based learning had put extra time and effort to understand the concepts and therefore, they have missed their commitments and responsibilities towards the respective sports clubs and societies during the exam period.

\section{Experiment and Result}

Through thematic analysis and participant, observation authors have observed that there is a direct effect of using animated characters in online teaching for the selected sample of undergraduate students. It was also observed that lessons taught using animation through zoom were a successful and effective strategy, which shows students engagement and shows the possibility of improving students' moral development [4]Further, it was observed that there is a lasting and positive influence of this strategy on their way of thinking and acquiring knowledge. Byusing an exam and a presentation as an assessment of learnt concepts, it was observed that the concepts taught by using $2 \mathrm{D}$ animations had a lasting impact. During the process of the research, it was observed that the students in the classroom tend to show emotions towards animations used in their lessons.For example, using cheerful and expressive movies and animated content in the classroom made them happy. This was connected to their psychological wellbeing [5]

\section{IV.CONCLUSION}

Through the findings, the authors have observed that the use of animation videos in the classroom was an effective way to engage the students in the lesson and to test the learning outcomes. As observed since there is a lasting impact on students sense of morality, and social development, findings support that using $2 \mathrm{D}$ animation as a learning tool not only effectively contribute as a technique of knowledge acquisition and learning retention but also has implication on enhancing their ability to express emotions through positive modifications in the behaviour and attitudes. Findings support the need to evaluate further on the use of innovative teaching techniques through digital platforms as this study forms the basis for the positive implications.

\section{REFERENCES}

[1] K. T. S. K. Sidath R. Liyanage, "Predicting the Academic Performance of Students Using Utility-Based Data Mining," Emerging Research and Opportunities, August, 2019.

[2] C. \&. G. J. S. Fadel, "Four-Dimensional Education for Sustainable Societies," Sustainability, Human Well-Being, and the Future of Education , pp. pp 269-281, 2018.

[3] T. Haydn, "Working to Improve Classroom Climate Using a Ten Point Scale and Focusing on the Development of the Classroom Management Skills of Individual Teachers," Creative Education, pp. 2351-2360, 2015.

[4] E. Jensen, Teaching with the Brain in Mind, Alexandria: questia.com, 2005.

[5] A. Bartsch, " Emotional Gratification in Entertainment Experience. Why Viewers of Movies and Television Series Find it Rewarding to Experience Emotions," Media Psychology, vol. 15, no. 10.1080/15213269.2012.693811, 2012. 